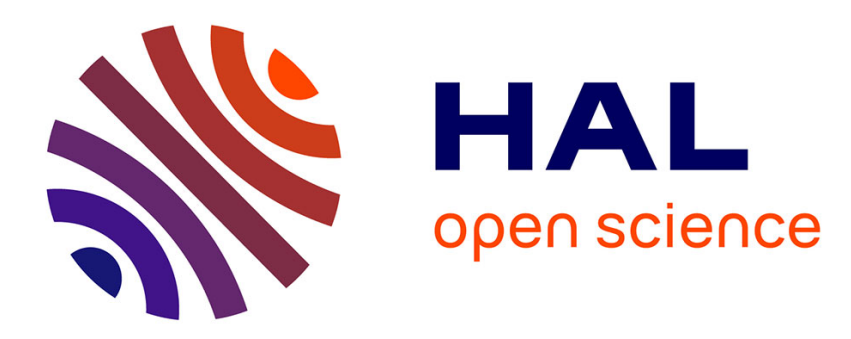

\title{
The long-term decline in terms of trade and the neolithisation of Northern Europe \\ Serge Svizzero
}

\section{To cite this version:}

Serge Svizzero. The long-term decline in terms of trade and the neolithisation of Northern Europe. Scandinavian Economic History Review, 2015, 63 (3), pp.260-279. 10.1080/03585522.2015.1008566 . hal-02150104

\author{
HAL Id: hal-02150104 \\ https://hal.univ-reunion.fr/hal-02150104
}

Submitted on 7 Jun 2019

HAL is a multi-disciplinary open access archive for the deposit and dissemination of scientific research documents, whether they are published or not. The documents may come from teaching and research institutions in France or abroad, or from public or private research centers.
L'archive ouverte pluridisciplinaire $\mathbf{H A L}$, est destinée au dépôt et à la diffusion de documents scientifiques de niveau recherche, publiés ou non, émanant des établissements d'enseignement et de recherche français ou étrangers, des laboratoires publics ou privés. 


\title{
The long-term decline in terms of trade and the neolithisation of Northern Europe
}

\author{
Serge Svizzero* \\ Faculté de Droit et d'Economie, Université de La Réunion, 15 Avenue René Cassin, BP 7151. \\ 97715 Saint Denis Cedex, France
}

\begin{abstract}
While agriculture spread quite rapidly from the Levant to most parts of Europe during the sixth millennium, its adoption was delayed to the fourth millennium in Northern Europe, an area inhabited by complex hunter-gatherers (HGs) - mainly the Ertebølle culture. This hiatus leads us to reject diffusion by migration or acculturation. It favours integrationist models of contact between foragers and farmers and attributes the shift to agriculture to social competition between HGs. We provide an alternative explanation of this shift, based on an economic mechanism related to trade between foragers and farmers. We demonstrate that the terms of trade of raw materials extracted and sold by foragers have a tendency to decline in the long term in relation to the food resources produced and sold by farmers. Neolithisation of Northern Europe can therefore be viewed as the outcome of a long-term process based on trade in which HGs voluntarily get involved without forecasting that it will, in the end, constrain most of them to give up their way of life. Such an explanation is consistent with the long period of contact between foragers and farmers provided by archaeological records and recent palaeogenetic studies.
\end{abstract}

Keywords: Neolithic diffusion; complex hunter-gatherer; terms of trade; extractive economy; Prebisch-Singer Thesis

\section{Introduction}

The shift from hunting and gathering to farming and animal rearing occurred during the Neolithic period which spans approximately from $10,000 \mathrm{BC}^{1}$ to $3500 \mathrm{BC}$. Following Vere Gordon Childe (1936), this shift has been labelled the so-called 'Neolithic revolution' since it has led to social and economic major changes in which one can find the origins of our current civilisation. Given the importance of the consequences of the Neolithic revolution, the latter has been extensively studied by academics for more than a century. Besides the consequences of this revolution, the main question studied in the literature is about its causes: for what reasons human have adopted agropastoralism whereas they were hunter-gatherers (HGs) for more than $99 \%$ of their life since the apparition of Homo sapiens. This question may in fact be divided in two separate but related questions.

\footnotetext{
*Email: Serge.svizzero@univ-reunion.fr

${ }^{1}$ Dates listed as 'BC' are in calibrated years
} 
The first one is about the transition from foraging to farming. How and why did HGs 'invent' plant cultivation and animal husbandry? This question has been widely studied by social scientists and, for three decades, also by economists. ${ }^{2}$ This question is of great interest because agriculture occurred independently - and in few millennia - in at least seven centres located worldwide ${ }^{3}$ despite various eco-geographic conditions. ${ }^{4}$

The second question is about the spread of agropastoralism from any of the seven centres mentioned above to other places. This process is called diffusion. Agriculture based on cultivated wheat and barley had emerged in the period between 9000 and 7000 BC in the Near East. Domestic livestock were soon added to the agricultural economy. Yet it did not remain a localised phenomenon, and it rapidly spread to Eastern Anatolia and South-eastern Europe to the north-west. The question is therefore, once agriculture has been introduced in one centre, what has been the future of the people - namely Mesolithic HGs - that were living in other places? Before 10,000 BC, hunting and gathering was the only way of life. At the end of the Neolithic period, around $3500 \mathrm{BC},{ }^{5}$ most European people were farmers and/ or pastoralists. Therefore, there are two possibilities. On the one hand, Mesolithic HGs have physically disappeared; in such case we have to explain why and how they disappeared. On the other hand, HGs have given up food procurement and have shifted to an economy based on food production. In this latter case, we have to specify if this shift was constrained or voluntary and why and how it occurred. In order to answer to these questions about the future of HGs during the Neolithic period, we need to study how diffusion really worked, which has always been a question of debate, not really solvable with known archaeological methods. Did people from the core invention area move en masse ${ }^{6}$ to other places bringing their innovations with them? Or did people from other places learn about innovations from trade or other relationships such as intermarriage? In other words, a major debate $^{7}$ in the study of earliest European farmers is whether they were colonists who settled in the major river valleys of North-Central Europe or whether they were local HGs who adopted domestic plants and animals coming from the Levant.

For Northern Europe, there is a generally accepted view about the transition to agriculture $^{8}$ combining folk migration and cultural diffusion and called the integrationist approach. ${ }^{9}$ Indeed, farming was introduced from Central Europe between 5400 and 5000 BC into Northern Poland and Germany by enclave-forming, isolated settlements of the $\mathrm{LBK}^{10}$ and derivative traditions. North-western Europe had been at the margin of LBK during the fifth millennium. Therefore, the explosive movement of LBK stopped before it reached the Atlantic and Baltic coasts. One

\footnotetext{
${ }^{2}$ For a complete survey of the archaeological and the economic literature on the transition, see Weisdorf, 'Foraging' (2005).

${ }^{3}$ The Levant, India, North China, Mesoamerica, New Guinea, North Africa, the Andes.

${ }^{4}$ Such conditions include climate, soil, rain fall, ecosystems, plants suitable for cultivation and animals suitable to domestication.

${ }^{5}$ In Central Europe, the Neolithic ends 2200 BC.

${ }^{6}$ After Ammerman/Cavalli-Sforza, 'Measuring' (1971), this massive folk migration is often called the 'wave of advance'.

${ }^{7}$ See e.g. Bogucki, 'Recent Research' (2001).

${ }^{8}$ Price, 'Introduction' (2000).

${ }^{9}$ Zvelebil, 'Agricultural Transition' (2001).

${ }^{10}$ LBK for Linearbandkeramik; see Section 2 for a complete presentation.
} 
reason for this delay must be attributed to the lack of soils suitable for cultivation. Another reason is the presence of substantial Mesolithic groups along these coasts of Europe. There is evidence of contact between these complex Mesolithic HGs - such as the Ertebølle culture ${ }^{11}$ - and early Neolithic farmers to the South. Following this long episode of contact between foragers and farmers are the first extensive farming communities in Northern Poland and Germany, Denmark, Southern Norway and Southern and Middle Sweden belonging to the Funnel Beaker (TRB) culture and dating from 4200 BC on the North European Plain and from 3900 BC in Southern Scandinavia.

Complex HGs - such as Ertebølle - are featured by a high degree of sedentism, high population density, more intensive food procurement, technological elaboration, development of exchange networks, social differentiation and the emergence of territorial claims. They are very far from simple HGs roaming all the day to barely meet their needs. Therefore, their transition to farming is of great interest because it does not seem to be the result of a voluntary process such as the one motivated by the quest of food resources. ${ }^{12}$ It is the aim of this paper to provide such explanation. For that purpose, we especially focus on the study of trade between complex HGs and farmers.

Many explanatory models ${ }^{13}$ of the transition to farming focus on social processes within the HG communities. In this literature, there seems to be a consensus that social competition within the Late Mesolithic HG communities prompted the adoption of crop cultivation and animal husbandry. However, this attention to internal social processes is limited to a descriptive level of analysis and the Mesolithic-Neolithic transition is simply described as the adoption of a Neolithic package. $^{14}$

Contact and exchange between foraging and farming communities was bound to play a key role as a vehicle for the adoption of farming. Characteristically, raw materials and products of hunting and gathering such as furs, honey and seal fat were exchanged by HGs for finished products $^{15}$ such as axes, ceramics ${ }^{16}$ and ornaments. Such structure of trade is similar to the one between developing and developed countries. The former are exporting commodities and raw materials while the latter are exporting manufactured goods. Dealing with international trade between both groups of countries, Singer ${ }^{17}$ and Prebisch ${ }^{18}$ examined data over a long period of time suggesting that the terms of trade for primary commodity exporters did have a tendency to decline. They concluded that it is the very structure of the market which is responsible for the existence of inequality in the world system. We assume that the structure of trade between foragers and farmers during the sixth to

\footnotetext{
${ }^{11}$ See Section 4 for a presentation of the Ertebølle culture.

${ }^{12}$ Fischer, 'Food' (2002).

${ }^{13}$ Zvelebil/Rowley-Conwy, 'Transition' (1984); Dennell, 'Hunter-gatherer' (1985); Verhart, Times (2000); Zvelebil, 'Agricultural Transition' (2001).

${ }^{14}$ Raemaekers, Articulation (1999).

${ }^{15}$ In the Ertebølle culture there is however no reliable evidence either for exchange of grain and cattle (Terberger et al., 'Late Hunter-gatherer' (2009) or for independent domestication of cattle (Scheu et al., 'Ancient DNA' (2007)).

${ }^{16}$ Even if there is limited evidence for exchange of ceramics; see e.g. Czekaj-Zastawny et al., 'Long Distance' (2011).

${ }^{17}$ Singer, 'Distribution' (1950).

${ }^{18}$ Prebisch, Economic Development (1950).
} 
the fourth millennium in Northern Europe was very similar to the one existing between developing and developed countries since the industrial revolution. ${ }^{19}$ Terms of trade were therefore unfavourable to foragers who, in the long term, have been constrained to adopt farming.

The paper is organised as follows. LBK, the first Neolithic culture in Europe, is presented in Section 2, which includes also a presentation of the debate about the origin of LBK. The migrationist approach of Neolithic diffusion is defined in Section 3 and its empirical evidence is assessed for the European continent. In Section 4, cultural diffusion is defined and assessed symmetrically. Contacts between foragers and farmers, as usually considered in the literature, are detailed in Section 5. Section 6 is devoted to the study of specialisation, trade and trade structure between Ertebølle foragers and LBK to TRB farmers. The longterm decline in terms of trade is explained in Section 7, which also includes the analysis of the resulting neolithisation process for Northern Europe. Section 8 concludes.

\section{LBK, the first Neolithic culture in the European continent}

Current evidence suggests that the Neolithic materialistic culture was introduced to Europe via Western Anatolia. As it is confirmed by genetic data, all Neolithic sites in Europe contain the plants and animals domesticated in south-west Asia. It is therefore widely accepted that the onset of agriculture in the Near East triggered a cultural change that diffused farming and associated technologies across Europe starting about 10,000 years ago. The information provided by archaeological remains and the trajectory of straight and short line paths suggest the estimated speed of agricultural spread was approximately 1 kilometre per year. ${ }^{20}$ Of course there were very significant regional variations in the rate of spread, e.g. unfavourable ecological and geographical factors caused a retardation of its spread to some parts of Europe.

The $\mathrm{LBK}^{21}$ culture (also called Bandkeramik or Linear Pottery Ceramic culture or simply abbreviated LBK) are the first true farming communities in Central Europe, dated between about 5400 and 4900 BC. The earliest LBK sites are located in the modern Balkan states about 5700 BC. Over the next few centuries, the sites are found in most North European countries, spreading from the Central European plain. On average, the LBK culture spread into Europe at a rate of 3.5-5 kilometres per year. LBK is considered to be the first Neolithic culture in the European continent because LBK people were the importers of agricultural products and methods, moving the first domesticated animals and plants from the Near East into Europe.

The very earliest LBK sites have lots of pottery shards with limited evidence of agriculture or stock-breeding. Later LBK sites are characterised by longhouses with rectangular plans, incised pottery and a blade technology for chipped stone tools. The tools include raw material of high-quality flints and traded obsidian. The LBK lived in small villages along streams or waterways characterised by large

\footnotetext{
${ }^{19}$ See e.g. Williamson, 'Globalization' (2008) for a presentation of the long-term trend of terms of trade between rich and poor countries.

${ }^{20}$ Ammerman/Cavalli-Sforza, 'Measuring' (1971).

${ }^{21}$ See Keeley/Golitko, 'First Farmers' (2004) for a complete presentation of the LBK culture.
} 
longhouses, buildings used for keeping livestock, sheltering people and providing work space.

\subsection{Origins of the LBK: demic diffusion versus cultural diffusion?}

The earliest LBK sites are found in the Starčevo-Körös culture of the Hungarian plain, around $5700 \mathrm{BC}$. From there, the early LBK spreads separately east, north and west. One of the central debates among scholars about the LBK is whether the people were migrant farmers from the Near East or local HGs who adopted the new techniques. In the literature, two schools of thoughts - namely the migrationist ${ }^{22}$ and the indigenist ${ }^{23}$ - proposed to account for the geographical spread of agriculture from the Levant to Europe by highlighting, respectively, the diffusion of people and of ideas. Despite their fundamental differences, both processes in fact represent gradual spread driven by individual random events, either human migrations or cultural exchange events.

In the demic diffusion model, ${ }^{24}$ the spread of technologies involved a massive movement of people. The demic diffusion is a kind of replacement model. It posits that there was a significant migration of farmers from the Fertile Crescent into Europe. Given their technological advantages, these migrants would have displaced or absorbed the less numerous hunting-gathering populace. Given the cultural diffusion model, on the contrary, the transition to agriculture is regarded essentially as a cultural phenomenon, involving the movement of ideas and practices rather than people. It is then assumed that agriculture reached Europe by way of a flow of ideas and trade between the Mesolithic European population and Anatolian farmers. There was no net increase in migration during this process, and therefore, modern Europeans are descended from the 'original' Mesolithic HGs. Consequently, the cultural diffusion model does not imply major changes in the composition of human genes in Europe as a result of migration from Asia Minor.

Genetic studies carried out on modern European populations have led to conflicting results from the early 1970s. However, according to new palaeogenetic evidence based on ancient mtDNA studies, ${ }^{25}$ there is strong evidence that the HGs of Central Europe had a completely different genetic profile (mtDNA) to the LBK people. Indeed these studies have suggested that the LBK populations shared an affinity with the modern-day Near East and Anatolia, supporting a major genetic input from this area during the advent of farming in Europe. These data are compatible with a model of Central Europe in the early Neolithic of indigenous populations plus major genetic inputs from expanding populations in the Near East. Thus, on a regional scale, these results support the 'leapfrog' colonisation model, where early farmers initially targeted the economically favourable loess plains in

\footnotetext{
${ }^{22}$ Childe, Man (1936), Ammerman/Cavalli-Sforza, 'Measuring' (1971), Neolithic Transition (1984).

${ }^{23}$ Dennell, European Economic Prehistory (1983).

${ }^{24}$ This model - the most popular among the migrationist approach - was first introduced by Ammerman/Cavalli-Sforza, 'Measuring' (1971). Their 'wave of advance' model proposed that population growth at the agricultural fringes coupled with local migrations would produce steady population expansions in all directions.

${ }^{25}$ Bramanti et al., 'Genetic Discontinuity' (2009); Haak et al., 'Ancient DNA' (2010).
} 
Central Europe. On the HGs side there are even some indications ${ }^{26}$ that the descendants of Mesolithic people maintained a foraging lifestyle in Central Europe for more than 2000 years after the arrival of farming societies.

Despite their respective interest, both approaches of diffusion can be challenged ${ }^{27}$ for the European case since they do not find unequivocal support in either the archaeological, ecological or demographic evidence. ${ }^{28}$

\section{Demic diffusion and its lack of evidence}

It is well known that both economic systems - food procurement and food production - have advantages and drawbacks. However, agriculture a long time ago essentially took over the world, and hunting and gathering is now found only in very marginal and supposedly 'backwards' area. Such situation is implicitly explained by the existence of a trade-off between having more leisure and better nutrition versus simply being able to feed more mouths. If the latter option wins out in the end, most explanations in the literature rely on a vision based, implicitly or not, on an evolutionary process. As with the development of a specie (a plant or an animal), the development of human societies is considered to be greatly determined by what strategies produce the most offspring.

\subsection{Demographic pressure}

Since agricultural societies simply fed more people, allowed for larger families and so could push out, absorb or slaughter the hunter-gathering societies in the long run, demographic pressure is generally considered to be the prime mover ${ }^{29}$ of the Neolithic expansion. Judging from the number of sites, the population in the Near East started increasing from 15,000 BC with the appearance of Natufian sites. This was marked by an increase in sedentariness and a broadened range of subsistence strategies. Apparently, the birth rate dramatically increased with the emergence of agricultural sedentary settlements. This is believed to be due to the changed social status of women and to better childcare, combined with the larger and more regular availability of a more nutritious food supply. However the presumed rapid population growth brought about by the emergence and development of farming has been challenged. ${ }^{30}$

\subsection{HGs-farmers competition}

There seems to be considerable evidence that relationships between the Mesolithic HGs in Europe and the LBK migrants were not entirely peaceful. Evidence for violence exists at many LBK village sites. Further, there are a fairly high number of LBK villages that evidence some kind of fortification efforts. ${ }^{31}$ However, most evidence of LBK violence is related to the late phase and therefore conflicts between

\footnotetext{
${ }^{26}$ Derived from examination (mtDNA sequence and isotope analysis) of Mesolithic and Neolithic samples from the Blätterhöhle site; Bollongino et al., '2000 Years' (2013).

${ }^{27}$ See Sections 3 and 4.

${ }^{28}$ Zvelebil, 'Agricultural Transition' (2001).

${ }^{29}$ Diamond, Guns (1997), 112.

${ }^{30}$ Zvelebil, 'Agricultural Transition' (2001), 4; Fischer, 'Food' (2002), 361.

${ }^{31}$ Golitko/Keeley, 'Beating Ploughshares' (2007).
} 
LBK communities ${ }^{32}$ rather than between HGs and LBK people are likely to be the reason of fortification efforts and evidence of traumatic injuries. Moreover, the presumed competition between HGs and farmers, which is implicit in the migrationist approach, does not find support in ecological evidence. Indeed, before the late Neolithic, there is no indication of extensive agriculture - such as woodland clearances and environmental degradation - i.e. no indication of competition between two economic systems that would have provided a rationale for relocation of $\mathrm{HG}$ societies. On the one hand, LBK farmers settled exclusively in specific areas that were suitable for agriculture, i.e. in fertile loess area and close to lakes or rivers. On the other hand, HG populations were much more attracted by coastal and lacustrine regions and along major rivers. The only explanation of possible conflicts between the two communities can be a parasitic relationship on the side of the HGs, where they steal goods and products from the farmers. ${ }^{33}$ However, even this latter explanation can be challenged: indeed, robbery has probably existed between the two communities but has led only to marginal conflicts.

\section{Cultural diffusion and its lack of incentive}

Although since Childe (1936) mass migration from Western Asia was deemed to be the dominant mechanism for Neolithic expansion into Europe, one may attach greater significance to the indigenous adoption of agriculture, described as cultural diffusion, driven by contacts between invading farmers and local foragers. Indeed, it is well documented $^{34}$ that exchange and trade over long distance occurred from the Mesolithic period onwards. Economic purposes, such as the ones involved in trade, are some of the main contributors to cultural diffusion. Such a claim is supported by the rapid spread of pottery production (during the Neolithic period) and of metalworking (after the Neolithic period) from the Levant to Europe as a result of trade.

If trade between HGs and farmers has probably occurred from the early Neolithic, it does not necessarily means that HGs gave up their way of life to shift towards agropastoralism. This is especially true if we consider complex societies of HGs, such as the Ertebølle culture of North Europe. In the sequel, we demonstrate that complex HG societies were sharing all features of agrarian societies, thus reducing the incentive to switch to agriculture. Moreover, the difficulties to survive encountered by the farmers ${ }^{35}$ are an additional rationale used to demonstrate that cultural diffusion, i.e. an HG's deliberate choice to adopt agriculture, is of little relevance.

\subsection{Complex HGs}

Until the 1960s, HG societies were mainly - or exclusively - seen from Hobbes' perspective. Indeed, Hobbes ${ }^{36}$ claimed that before the appearance of modern governments and states, life was 'solitary, poor, nasty, brutish and short'. Such a

\footnotetext{
${ }^{32}$ Golitko/Keeley, 'Beating Ploughshares' (2007), 340.

${ }^{33}$ Dennell, 'Hunter-gatherer' (1985).

${ }^{34}$ Chapman, 'Approaches' (2008); Czekaj-Zastawny et al., 'Long Distance' (2011).

${ }^{35}$ See e.g. Weisdorf, 'First Farmers' (2009).

${ }^{36}$ Hobbes, Leviathan ([1651] (2010)).
} 
vision has been obviously adopted by various subsequent authors. In this view, the economy and society of HG - thereafter called 'simple HGs' - are described by four features. ${ }^{37}$ People were poor. They were roaming all the time to get food and their technology, hunting and gathering, resulted in low productivity. Their technology also constrained them to have a nomadic way of life in order to avoid starvation. Since they were nomads, it was impossible for them to have more than one child per family every four or five years. As a result, their population had a low density and they were organised in small groups or 'bands'. Finally, since their method of food procurement provided no surplus due to their deficient technology and the lack of division of labour, their society was assumed to be egalitarian.

In the 1980s, ethnological studies of recent HG societies have shown that if simple HGs had existed during the Palaeolithic period, they were probably the exception rather than the rule after the global warming featuring the Holocene era. Indeed, many Mesolithic $\mathrm{HG}$ societies were associated with a well-developed economy $^{38}$ and shared all the features of agrarian societies, except that food was not produced. These societies have been labelled 'complex HGs' ${ }^{39}$ Complex HG societies have existed in all continents and the most famous are the indigenous societies of the North-west coast of America, the Ertebølle of Mesolithic Southern Scandinavia and the Natufian of the late Epipalaeolithic Levant. To obtain an economic surplus, these societies had relatively complex technologies and kept substantial inventories of items. As a result of their technologies and their ability to store food, they showed considerable sedentism. Due to their sedentary way of life and their greater amount of available food, their population had a higher density. As a correlate to the distribution of the economic surplus and the increased division of labour, their societies displayed a non-egalitarian allocation of wealth. In other words, complex HG societies are at the opposite end of the spectrum to simple HG ones. Therefore, they have been widely referenced in the evolutionist literature as providing a bridge between simple $\mathrm{HG}$ societies and agrarian societies.

\subsection{The Ertebolle culture}

The Ertebølle culture is the name given to the Late Mesolithic/Early Neolithic communities of Northern Europe, dated between 5400 and 3900 BC, consisting of fisher-HGs who adopted pottery but not agriculture from their neighbours. The Ertebølle people were very adept at marine resources exploitation, including building fish weirs. Many of the Ertebølle sites (such as the type site Ertebølle, Jutland, Denmark) were built on enormous middens of oyster shell, indicating shellfish were at least a quite substantial part of the Ertebølle diet. In addition to marine resources, they also hunted and gathered a wide range of animals, including wild pig, bird species and marine mammals. The Ertebølle society was therefore affluent and sedentary or quasisedentary. Both features allowed this society to have a population with a quite high density. The existence of an economic surplus, combined with food storage led to social and economic inequalities in the Ertebølle society. The Ertebølle culture

\footnotetext{
${ }^{37}$ Service, Hunters (1966).

${ }^{38}$ Svizzero, 'Pre-Neolithic Economy' (2014).

${ }^{39}$ See Price/Brown, Prehistoric hunter-gatherers (1985).
} 
replaced the earlier Kongemose culture of Denmark. It is divided into an early phase from 5400 to $4500 \mathrm{BC}$, and a later phase from 4500 to $3950 \mathrm{BC}$. The Ertebølle culture started earlier than the LBK culture, food producers whose northernmost border was located just to the south. The Ertebølle did not practice agriculture. ${ }^{40}$ Shortly after 4100 BC the Ertebølle began to expand along the Baltic coast. Shortly thereafter it was replaced by the TRB culture.

\subsection{The low attractiveness of the farming way of life}

It is often believed that the initial effect of the shift from hunting-gathering to agriculture was an increase in food production. Societies that adopted agriculture were able to produce far more food in a given territory than those that relied on foraging. This increase in productivity could be used either to expand the economic surplus or expand population, with both usually occurring. However, recent studies have deeply challenged this vision.

First, in Mesolithic Europe, and as illustrated by the Ertebølle culture, HGs were not mobile and organizationally simple. ${ }^{41}$ On the contrary, they tended towards socio-economic complexity, including sedentism. Similarly Neolithic European farmers, as illustrated by the LBK culture, were not super-productive and sedentary. On the contrary, they were often mobile and with a mixed-economy combining hunting-gathering and farming. The cultural diffusion of the Neolithic revolution, i.e. the deliberate choice of HGs to switch towards agriculture, finds therefore little support.

Second, it was often believed that farmers were affluent and HGs were poor. However, the early agriculturists had to work more hours, were more prone to lethal disease and malnutrition, and had to endure less egalitarian social structures than HG societies. ${ }^{42}$ Since there are almost no indications of increased standards of living immediately after the agricultural transition, why did European complex HG decide to give up their way of life in order to adopt agriculture?

Third, HG women were not necessarily attracted by the farming way of life, as it is often assumed in the literature. ${ }^{43}$ Indeed, when women belonged to complex HG societies, they had a sedentary or quasi-sedentary way of life. Therefore, no longer being restricted by the constraint of the nomadic way of life, women were able to have more children, just as women of farming communities did. Moreover, the domestication of animals and the shift to agriculture was accompanied by major changes in the roles and relationships between men and women and patterns of childrearing. This key change in gender relations also contributes to explain why the shift towards agriculture was not very attractive for HG women.

\section{The integrationist approach: Modelling HGs/farmers contact}

Proponents of migrationist and cultural models of diffusion acknowledge that there is a spectrum of intermediate scenarios involving mixed models: settlements were founded by a mixture of farmers whose ancestors originally came from the Near

\footnotetext{
${ }^{40}$ Sørensen/Karg, 'Expansion' (2012).

${ }^{41}$ Zvelebil, 'Agricultural Transition' (2001).

${ }^{42}$ Weisdorf, 'Foraging' (2005), 562.

${ }^{43}$ Zvelebil, 'Innovating Hunter-Gatherers' (2008), 21.
} 
East and indigenous HGs. The question is, therefore, whether the dispersing farmers were few, as in the cultural diffusion model or many, as in the demic diffusion model. To answer this question, analysis of genetic variation among modern individuals is providing insight into prehistoric events. Comparisons of levels and patterns of genetic diversity with the predictions of models based on archaeological evidence suggest that the spread of early farmers from the Levant was probably the main episode in the European population history. However, both older and more recent processes have left recognisable traces in the current gene pool. ${ }^{44}$ Most recent studies, ${ }^{45}$ as implied by archaeological data, show that cultural diffusion explains between $30 \%$ and $40 \%$ of the spread rate of the Neolithic transition in Europe. Thus, cultural diffusion cannot be neglected, but demic diffusion was the most important mechanism in this major historical process at the continental scale. However, there is no unique model of mixed diffusion: while the overall effect is diffusion into Europe from the south-east, detailed spatial analysis reveals fascinating local variations. ${ }^{46}$ Such variability is related to time and space, as illustrated by the difference between the neolithisation of Central Europe (mid of the sixth millennium BC) and the North (4000 BC). As stated previously, according to new palaeogenetic evidence based on ancient mtDNA studies, ${ }^{47}$ there is strong evidence that the HGs of Central Europe had a completely different genetic profile (mtDNA) to the LBK people.

Mixed models of diffusion - combining migrationist diffusion and cultural diffusion - are constitutive of the integrationist approach. ${ }^{48}$ In this approach, the diffusion of agriculture results from various combinations of three mechanisms. First, it relies on leapfrog colonisation rather than on massive folk migration or demic diffusion. This denotes a selective colonisation of an area by small groups, who target optimal areas for cultivation (usually, loess soils). These groups are thus forming an enclave settlement among native inhabitants or HGs. Second, it considers frontier mobility, i.e. small-scale movement of population within contact zones between HGs and farmers, occurring along the established social networks, such as trading partnerships, kinship lines and marriages alliances. Third, contacts exist through trade within the framework of regional, or extra-regional trading networks. These networks served as channels of communication through which innovations spread from farmers' communities to HGs.

As demonstrated previously, archaeologically, ethnographically and ecologically, the migrationist approach as well as the cultural one finds little evidence to explain the agricultural diffusion in Europe; therefore, one can conclude the superiority of the integrationist approach. ${ }^{49}$

\footnotetext{
${ }^{44}$ Barbujani/Bertorelle, 'Genetics' (2001), 22.

${ }^{45}$ Fort, 'Synthesis' (2012).

${ }^{46}$ Gkiasta et al., 'Neolithic Transition' (2003).

${ }^{47}$ Bramanti et al., 'Genetic Discontinuity' (2009); Haak et al., 'Ancient DNA' (2010);

Bollongino et al., '2000 Years' (2013).

${ }^{48}$ Zvelebil, 'Agricultural Transition' (2001).

${ }^{49}$ Zvelebil, 'Agricultural Transition' (2001), 5.
} 


\subsection{Outcomes of contacts between foragers and farmers}

A consequence of the superiority of the integrationist approach has been, from the mid-1980s, an increase of the number of models ${ }^{50}$ devoted to the interactions between foragers and farmers. The first of these models was the 'availability model'. ${ }^{51}$ While it was more descriptive than explanatory, many subsequent models of contact ${ }^{52}$ can be defined by comparison with it. This model considers three successive phases. In the first one, or the 'availability phase', contacts between foragers and farmers exist but both communities remain independent. In the second one, or the 'substitution phase', the HGs incorporate from 5\% to $50 \%$ of domesticates (plants and animals) into their economy. In the third and last one, the 'consolidation phase', the production of food becomes dominant. In other words, hunting and gathering are no long important for food supply and are progressively disappearing.

In the various models ${ }^{53}$ of the neolithisation process, there are four possible outcomes $^{54}$ of contacts between foragers and farmers, ranging from replacement, integration, survival to reversion. The meeting of two completely different cultural, social and economic systems must have had far-reaching repercussions on the societies involved. However, the results of first stage contact are of less importance. ${ }^{55}$ They affect mainly the social system, as opposed to the economic system. Indeed, there are mutual exchanges of goods, but economic motives are absent or very secondary. Both populations are not interested in food, since for each population, their own food is adequate for their daily subsistence. They are much more interested in objects - also called 'exotic' - that may be used in the prestigious system. Such objects could be, for example, on the one hand fur and amber for farmers and, on the other hand, potteries and adzes for foragers. The second stage contact is much more important because structural economic changes occur. This mainly comes from the fact that exchanges are less opportunistic and more structured, i.e. much more based on a behaviour defined by what we call, in modern language, a Homo æeconomicus. These exchanges may lead to one of three different relationships between foragers and farmers, dependence, symbiosis and independence. However, the various models of the neolithisation process do not provide an endogenous explanation of the economic mechanism leading to one of these three relationships. On the contrary, it is often assumed that the major change is social ${ }^{56}$ and concerns mainly - not to say exclusively - the HG society. Moreover these models often reject rational economic behaviour for HGs. ${ }^{57}$

\footnotetext{
${ }^{50}$ See Amkreutz et al., 'Diverging Trajectories' (2008) for a synthetic and comparative presentation of some of the main models of the neolithisation process.

${ }^{51}$ Zvelebil/Rowley-Conwy, 'Transition' (1984).

${ }^{52}$ E.g. Dennell, 'Hunter-gatherer' (1985), Verhart, Times (2000).

${ }^{53}$ Zvelebil, 'Agricultural Transition' (2001), 7, Table 1.

${ }^{54}$ Dennell, 'Hunter-gatherer' (1985) considers a more detailed model, including eight various HG/agricultural frontier situations.

${ }^{55}$ See Verhart, Times (2000), 31, for conclusions about first stage contact derived from various ethnographic data.

${ }^{56}$ Given the seminal work of Bender, 'Gatherer' (1978) on social competition as a major reason of the Neolithic transition. See also Verhart, Times (2000), 42 and Fischer, 'Food' (2002) for a complete statement of the consequences of social competition induced by trade. ${ }^{57}$ As stated by Fischer, 'Food' (2002), 384: 'With the socio-economic explanatory model it is suggested that in the evolution of human society rational calculation of labor input and subsistence output may have been overruled by an inherent desire for power, prestige, nutritional variation and social living'.
} 
However there is no obvious reason to consider that such social competition, on the one hand appears only in HG society after the contact with farmers, and not before, and on the other hand, that it only concerns the HG society and not the farmers' one. In fact many reasons lead us to reject the social competition explanation. The archaeological arguments for social competition are not conclusive and the incorporation of social competition in the explanation of the MesolithicNeolithic transition in the case of Ertebølle is indicative of the view we have on contemporary society. ${ }^{58}$ Indeed, it is often assumed that some goods were sought after merely because they were exotic, engendering competition and destabilisation in $\mathrm{HG}$ societies. However, there is no archaeological reason to assume that exotics were regarded as in any way special by their Mesolithic users. We may also add that in Northern Europe, the transition to farming occurred after as many as 1500 years of contact between foragers and farmers. If these contacts had induced competition among HGs, the shift towards agriculture would have been completed in a shorter period of time, e.g. two or three generations. We therefore have to find another explanation consistent with a very long-term transition to agriculture.

\section{Division of labour and trade between Ertebølle foragers and LBK to TRB farmers}

In the sixth and fifth millennia, Central and North Europe were involved with a subsistence dualism - hunting-gathering versus agropastoralism - and with a cultural dualism - Mesolithic versus Neolithic. Indeed, the first Neolithic communities - the LBK culture - appeared in these regions about the mid-sixth millennium, and then spread from the Paris basin to Western Ukraine and from Southern Transdanubia to certain areas of the North European plain. During the same period, HG communities - especially the Ertebølle culture - continued to live there, particularly in the lowland zone. Both dualisms began to change around $4000 \mathrm{BC}$. On the one hand, the LBK disappeared from Central Europe at the beginning of the fifth millennium and various Neolithic groups developed in the areas previously occupied by LBK populations. On the other hand, among these various Neolithic groups that appeared around $4000 \mathrm{BC}$ was the Funnel Beaker culture, also called TRB. ${ }^{59}$ People of the TRB culture were the first farmers of much of Northern Europe. Funnel Beaker sites are dated between about 4000 and 2800 BC. Over the first half of the fourth millennium BC, the TRB gradually encompassed Southern Scandinavia, the Northern part of Central Europe - from the Netherlands to the Polish lowlands. Therefore, the spread of the TRB may be referred to as the second stage of neolithisation, while the first stage was associated with the LBK culture.

The neolithisation of Central and Northern Europe, as described above - i.e. through two stages, LBK and then TRB - helps us to understand how the Ertebølle culture has evolved over time. During the early Ertebølle culture (sixth millennium and part of the fifth millennium), agriculture spreads to most of Northern Europe, right up to the Southern border of the Ertebølle culture. Therefore, contacts between LBK farmers and Ertebølle HGs have occurred. During the late Ertebølle culture (part of the fifth millennium and the beginning of the fourth millennium), TRB have replaced LBK; contact continued to occur between TRB farmers and Ertebølle HGs

\footnotetext{
${ }^{58}$ Raemaekers, Articulation (1999), Chapter 5.

${ }^{59}$ TRB for the abbreviation of its German name, Tricherrandbecher or Trichterbecher.
} 
until 3900 BC when agriculture was finally introduced in Southern Scandinavia, ${ }^{60}$ i.e. until the Ertebølle culture disappeared.

\subsection{Trade between forager communities}

In Northern circum-Baltic Europe, ${ }^{61}$ characteristically variable spatial and seasonal distribution of natural resources elicited a dual technological and economic response, comprising strategies of diversification and specialisation. Economic diversification consisted of encounter foraging of a wide range of resources. Economic specialisation consisted of interception of seasonally aggregated migratory resources.

It should be noted that trade - which can be seen as a form of social storage - is one of the four ${ }^{62}$ strategies of risk-reducing mechanisms available to foragers in order to manage seasonal and inter-annual variation of food resources. Therefore, before they had contact with Neolithic farmers, Northern European HG communities were already trading. Indeed and even if these communities of HGs were sedentary, they were involved in long-distance trade using the Northern European marine coastal routes and extensive river network, reinforced by seal hunting and production of seal oil as a locally produced trading commodity. They also engaged in long-distance trade, represented by a variety of exotic materials: amber, flint, greenstone and pottery. Specialised exploitation of seal and other coastal resources increased in the late Mesolithic and among ceramic-using HGs. This is evident from faunal data, site locations and human dietary analyses. Moreover, one may suggest that the adoption of ceramics facilitated in a major way the processing and storage of seal oil and so encouraged specialisation and trade.

\subsection{Specialisation and trade between foragers and farmers}

Farmers required large quantities of stone for making axes and other tools for forest clearance, cultivation, working timber for constructing houses, trackways and fences and other purposes. Social relations among farmers and complex HG communities demanded a supply of materials, such as shells, attractive stone, amber, gold and copper, which could be made into personal ornaments and display goods, as well as exotic artefacts such as nonlocal pottery. During the fifth to third millennia these needs promoted the development of trading networks ${ }^{63}$ to ensure the regular supply of these goods.

In Central and North Europe, the first stage contact between Neolithic farmers ranging from LBK to subsequent TRB cultures - and complex HGs - such as the Ertebølle culture - have led to exchange of goods. ${ }^{64}$ Probably the first exchanges were about prestigious goods, i.e. goods that existed in one community but not in the

\footnotetext{
${ }^{60}$ In Denmark, it appears that stock raising and cereal cultivation were introduced at about the same time as the shift from the Ertebølle Culture to the TRB culture, approximately 3950 BC. This also holds for the northeastern part of the Ertebølle area, Scania and its immediate vicinity. See Fischer, 'Food' (2002) for a complete presentation of neolithisation of Denmark and South Scandinavia, and Sørensen/Karg, 'Expansion' (2012) for a more recent statement of this process.

${ }^{61}$ Zvelebil, 'Innovating Hunter-Gatherers' (2008).

${ }^{62}$ The three other strategies are mobility, diversification and storage.

${ }^{63}$ See e.g. Czekaj-Zastawny et al., 'Long Distance' (2011).

${ }^{64}$ Chapman, 'Approaches' (2008).
} 
other. For foragers, such goods can include raw materials (amber), forest products (honey) and animal resources (furs, antlers). For farmers, such goods can include polished stone axes, ${ }^{65}$ adzes and pottery. 'Alpine Jade' was used for axe production in the Western Alps between the end of the sixth and the first half of the third millennium BC; the distribution of these axes in Denmark, Southern Sweden and Northern Germany confirms long-distance exchanges between Neolithic and Mesolithic communities. ${ }^{66}$

However, many similar or substitute products existed in both communities. Once prestigious goods have been exchanged, trade has concerned these substitute products. The latter can be divided in two groups. The first group includes goods that are imperfect substitutes. Concerning food resources, it could be cereals and legumes for the farmers' side and various wild plants for the foragers' side. The second group includes goods that are quasi-perfect substitutes such as meat provided by animal husbandry for the farmers' side and by game hunting for the HGs' side.

Foragers and farmers communities trade with each other when, on their own, they do not have the resources, or capacity to satisfy their own needs and wants. By developing and exploiting their domestic scarce resources, communities can produce a surplus, and trade this for the resources they need. Goods and services are likely to be traded for several reasons. Purchased goods may be cheaper, or of better quality. They may also be more easily available or simply more appealing than locally produced goods. In many instances, no local alternatives exist, and buying is essential. As first analysed by Adam Smith, ${ }^{67}$ the production of goods and services in communities that need to trade is based on two fundamental principles, the division of labour and specialisation. When applied to different communities, a division of labour means that communities produce just a small range of goods or services. Specialisation is the second fundamental principle associated with trade, and results from the division of labour. Given that each community is given a specialist role, it is likely to become an efficient contributor to the overall production. Hence, specialisation can generate further benefits in terms of efficiency and productivity. Specialisation is increased when communities use their scarce resources to produce just a small range of products in high volume. This allows a surplus of goods to be produced, which can then be sold to the other community. This means that goods and resources must be bought from the other community that have also specialised, and produced surpluses of their own.

As demonstrated for international trade, ${ }^{68}$ the total output - i.e. the output of both communities in our case - would increase when the principle of comparative advantage $^{69}$ is applied by communities to determine what goods and services they should specialise in producing. In other words, if communities apply the principle of comparative advantage, combined output will be increased in comparison with the output that would be produced if the two communities remained in autarky. Both communities have therefore mutual advantages to develop trade of goods resulting from specialisation according to comparative advantages. The following question in

\footnotetext{
${ }^{65}$ Fischer, 'Food' (2002), 373-76.

${ }^{66}$ Klassen, 'Axes' (2012).

${ }^{67}$ Smith, Inquiry ([1776] (2008)).

${ }^{68}$ Ricardo, Principles (1817).

${ }^{69}$ Comparative advantage relates to how much more productive or cost efficient one producer is than another.
} 
our special case is what were the comparative advantages of foragers and of farmers? Without loss of generality, we may consider that each community has two groups of economic activities, ${ }^{70}$ one related to food resources and the other one being about non-food resources. Concerning food resources, it is obvious that the labour productivity of agro-pastoralists is higher than the labour productivity of HGs. Thus, farmers have an absolute advantage in the production of food resources. For the non-food resources, the comparison is less obvious, mainly because most goods produced by both communities are different goods or low substitutes. Anyway, since farmers have an absolute - and hence implicitly a comparative - advantage in the production of food resources, they should specialise in this activity. In a symmetric way, foragers become specialist in the production of non-food resources. ${ }^{71}$ Based on such specialisation, ${ }^{72}$ trade between the two communities is consistent with the 'substitution phase' or the second stage contact.

\section{Deteriorating terms of trade and neolithisation}

In order to explain how the neolithisation process has occurred, i.e. why the Ertebølle culture has finally disappeared, we must therefore explain why the specialisation of both communities has been more intensive over time. For that purpose, we examine the causes and the consequences of the trend of the terms of trade.

A community's terms of trade ${ }^{73}$ measures a community's sales prices in relation to its purchases prices. We claim that farmers' terms of trade improved while they worsened for foragers and this evolution led to the final stage of the neolithisation process. When a community's terms of trade improve, it means that for every unit of goods sold it can buy more units of goods. So potentially, a rise in the terms of trade creates a benefit in terms of how many goods need to be sold to buy a given amount of purchased goods. A worsening term of trade indicates that a community has to sell more to purchase a given quantity of products. For foragers, the unfavourable evolution of terms of trade can be explained from both sides of a market analysis.

\subsection{Productive economy versus extractive economy}

Let us first consider the supply side. We have previously assumed that both communities had economic activities related to food resources and to non-food

\footnotetext{
${ }^{70}$ Indeed, our conclusion still holds if we consider more than two groups of activities for each community; similarly, Ricardo, Principles (1817) has demonstrated his theorem on international trade and comparative advantage in considering two countries trading two commodities.

${ }^{71}$ It should be noted that this does not mean that foragers give up food procurement, at least during a while. Becoming a specialist of an economic activity simply means that more scarce resources - mainly labour - are devoted to this activity.

${ }^{72}$ It should be noted that our assumption about specialisation is not crucial for the main conclusion of the paper. Indeed, whatever the economic activities in which foragers get specialised (e.g. food resources rather than non-food resources), our conclusion still holds because all activities of foragers' economy are extractive ones - see Section 7.

${ }^{73}$ In the economic literature, 'terms of trade' refers to international trade and measure a country's exports prices in relation to its imports prices. In this paper, there is no country and therefore no international trade. Consequently, it would be more appropriate to refer to 'the structure of relative prices' rather than to 'the terms of trade'.
} 
resources. However, a major difference exists between the two economic systems. Indeed, farmers have an economy based on production: food resources are produced (by means of plant cultivation and animal domestication) and non-food resources are also produced (e.g. pottery, stone axes, weaving). On the contrary, foragers have an extractive economy, i.e. a resource-based economy dependent on harvesting or extracting natural resources. Indeed, food resources are not produced, but obtained from the wild through hunting, gathering, collecting and fishing. Non-food resources (furs, amber, seal fat, forest products) are not produced as well, but extracted from nature and can be considered as raw materials. We therefore have two different economic systems, a productive economy and an extractive economy. However, both economies are based on the same input, namely labour. Comparison of both economic systems is then possible through the comparison of the marginal productivity of labour in each one. Farming exhibits, at worst, constant returns to labour, a fair assumption given the abundance of suitable land at that time. We may even consider that with the introduction of some innovations, the productivity of labour in agriculture is increasing. For foragers on the contrary, labour productivity is decreasing in both sectors, i.e. for food and non-food-resources. This comes from the fact that the resources extracted by foragers are non-renewable or at least exhaustive. More precisely these resources are 'produced' by nature. At any time, a given stock of these resources is available and each extraction by foragers leads to a reduced level of the remaining stock. More labour will be needed in the future to extract the same amount of resources, i.e. the marginal productivity of labour is decreasing. Moreover, if extraction is too important, it may reach the carrying capacity of a given resource and then result in its extinction. ${ }^{74}$ In the $\mathrm{HG}$ economic system, overexploitation of resources may often be the outcome since there is no private property, ${ }^{75}$ i.e. the tragedy of the commons can easily happen. The marginal productivity of labour is therefore constant - at worst - in the productive economy of farmers and decreasing in the extractive economy of foragers. Since labour is the only scarce input in both economic systems, its productivity determines the cost of production and then the price of output. We have therefore demonstrated that, over a long period of time, the terms of trade of raw materials (or non-food resources) extracted and sold by foragers have a tendency to decline ${ }^{76}$ in relation to the food resources produced and sold by farmers.

\subsection{The Singer-Prebisch Thesis}

Let us now consider the demand side of the market. For that purpose, we may adapt to our particular situation - trade between foragers and farmers - the SingerPrebisch Thesis. ${ }^{77}$ This thesis is well known in the literature on economic development of countries; it forms the basis of economic dependency theory. The thesis states that, over time, the terms of trade for commodities and primary

\footnotetext{
${ }^{74}$ Smith, 'Primitive Hunter Culture' (1975) considers, for example, that the megafauna extinction results from overkill.

${ }^{75}$ North/Thomas, 'First Economic Revolution' (1977).

${ }^{76}$ The same conclusion would be reached in a situation with diminishing returns to labour on agriculture. The only additional requirement would then be that the labour productivity in agriculture decline marginally less than hunting-gathering productivity.

${ }^{77}$ Prebisch, Economic development (1950) and Singer, 'Distribution' (1950).
} 
products deteriorate relative to manufactured goods. This hypothesis contributed to the general view that it was dangerous to rely on raw materials to secure growth and development. A common explanation for the phenomenon is the observation that the income elasticity of demand for manufactured goods is greater than that for primary products. Therefore, as incomes rise, the demand for manufactured goods increases more rapidly than demand for primary products. In our particular case, we may similarly assume that the income elasticity of demand for food resources produced by farmers is greater than that of raw materials extracted by foragers. Once again, this means that just to keep their standard of living and maintain the existing development gap, foragers relying on extracting raw materials, whose terms of trade decline, must continually increase output.

\subsection{Foragers' strategies and neolithisation}

On both sides of the market we have economic mechanisms explaining endogenously that foragers' terms of trade are worsening with the passage of time. In other words, foragers and farmers were initially expecting mutual gains from trade based on the division of labour and specialisation according to their respective comparative advantage. However, it appears that, due to unfavourable terms of trade, trade is not in favour of foragers. Once foragers realise that trade is not in their favour, they may adopt one of the three following strategies. ${ }^{78}$

First, they may decide to give up food procurement in order to concentrate all their labour forces on the extraction of non-food resources they trade with farmers. In this case, specialisation is total and foragers are now completely dependent on agriculture for their diet. In other words, the HG economy - as initially defined with respect to food resources - disappears and the neolithisation process is complete. However, such a situation is not very well suited to describe what has happened in Northern Europe. Indeed, total dependence would have implied a rapid transition from foraging to farming whereas such transition spanned during approximately 1500 years.

Second, they may choose reversion. In that case, they stop trading with farmers and return to their original way of life. If, from a social point of view, such outcome - namely independence - is possible, it is less likely from an economic point of view. Indeed, foragers should decide to work in economic activities where the productivity of their labour is higher and we know that the labour productivity associated with food procurement is very low, compared for instance to labour productivity in agriculture. It is however possible that some cases of reversion have occurred but they probably existed during short periods of time.

Third, they may choose a more symbiotic relationship with farmers. Some foragers may continue to extract raw materials and to trade with farmers. Other foragers may decide to give up their way of life and to turn to economic activities associated with higher level of the labour productivity. In fact, many choices are possible for them, notably ex-foragers may become farmers. Moreover, the development of the agrarian economy provided many job opportunities since it involved the emergence of non-food specialists. ${ }^{79}$ Therefore ex-foragers may also be

\footnotetext{
${ }^{78}$ Verhart, Times (2000), 32.

${ }^{79}$ Weisdorf, 'Stone Age' (2003).
} 
involved in 'industrial activities' such as handcrafts, pottery, weaving, tools fabrication, dwellings building, ships building (...) since the development of these activities is very complementary with the development of agriculture and settled life. They may also find jobs in the service sector, such as in the transport, the administration, the army (...) since, once again, this sector and agriculture are complementary. In this symbiotic scheme, neolithisation is the outcome of a process based on trade in which HGs voluntary get involved without forecasting that it will, in the end, constrain most of them to give up their way of life. We therefore view neolithisation of Northern Europe as the involuntary outcome of a process based on trade. Moreover, such explanation seems to us more convincing than social competition between HGs since it is a long-term process, i.e. it is consistent with the long period of contact between foragers and farmers provided by archaeological records. Our conclusion seems also reinforced by a recent archaeogenetic study ${ }^{80}$ showing that the Scandinavian Neolithic farmers exhibited an important degree of HG-related admixture while, in contrast, Scandinavian HGs displayed no significant evidence of introgression from farmers. In other words, this suggests that there has been an asymmetrical gene flow between HGs and early farmers in Scandinavia. Neolithic farming communities seem to have absorbed hunter-gatherers while advancing north through Europe while HG groups show no signs of absorbing Neolithic people.

\section{Concluding comments}

In Northern Europe, exchange and trade between complex foragers (Ertebølle culture) and farmers' communities (from LBK to TRB) have spanned approximately 1500 years, from 5400 to 3900 BC. Despite these numerous contacts - which are well documented by archaeological records - transition to farming has occurred only at the end of a long-term process. Therefore, the neolithisation cannot be considered as the outcome of a short-term process such as the one implied by social competition between HGs. It cannot also be considered as the result of a deliberate choice done by HGs - who finally recognised the superiority of agriculture - because they could have done it more quickly.

We provide an explanation of the neolithisation process in Northern Europe which avoids such shortcomings. Indeed, for us the neolithisation is the involuntary issue of a long-term process based upon trade between foragers and farmers. Both communities organised trade between them and get specialised according to their comparative advantages. However, foragers' economy is extractive, i.e. is associated with a decreasing productivity of labour. Moreover, the demand for the goods extracted and sold by foragers has low income elasticity. Given both features of their economy, foragers have faced worsening terms of trade in the long-term. Trade was not therefore in their favour, and this led them - or at least most of them - to finally give up their way of life, i.e. to adopt agriculture.

\section{Acknowledgements}

The author wishes to thank two anonymous reviewers for their helpful comments and suggestions. The usual caveat applies.

\footnotetext{
${ }^{80}$ Skoglund et al., 'Genomic Diversity' (2014).
} 


\section{References}

Amkreutz, Luc/Vanmontfort, Bart/Verhart, Leonardus (2008), 'Diverging trajectories? Forager-farmer interaction in the southern part of the Lower Rhine area and the applicability of contact models', in Creating Communities. New Advances in Central European Neolithic Research, ed. by D. Hofmann/P. Bickle, Oxford: Oxbow Books, 11-31.

Ammerman, Albert J./Cavalli-Sforza, Luca L. (1971), 'Measuring the rate of spread of early farming in Europe' in Man 6, 674-688.

Ammerman, Albert J./Cavalli-Sforza, Luca L. (1984), The Neolithic Transition and the Genetics of Populations in Europe, Princeton: Princeton University Press.

Barbujani, Guido/Bertorelle, Giorgio (2001), 'Genetics and the population history of Europe' in Proceedings of the National Academy of Science 98, no. 1, 22-25.

Bender, Barbara (1978), 'Gatherer hunter to farmer: A social perspective' in World Archaeology 10, 204-222.

Bogucki, Peter (2001), 'Recent research on early farming in Central Europe' in Documenta Praehistorica XXVIII, 85-97.

Bollongino, Ruth et al. (2013), '2000 years of parallel societies in stone age Central Europe' in Science Express 342, 479-481.

Bramanti, B. et al. (2009), 'Genetic discontinuity between local hunter-gatherers and Central Europe's first farmers' in Science 326, 137-140.

Chapman, John (2008), 'Approaches to trade and exchange in earlier prehistory: Late Mesolithic - Early Bronze Age' in Prehistoric Europe: Theory and Practice, ed. by A. Jones, Oxford: Wiley-Blackwell, 333-355.

Childe, Vere Gordon (1936), Man Makes Himself, London: Watts.

Czekaj-Zastawny, Agnieska/Kabacinski, Jacek/Terberger, Thomas (2011), 'Long distance exchange in the Central European Neolithic: Hungary to the Baltic' in Antiquity 85, 43-58.

Dennell, Robin (1983), European Economic Prehistory, London: Academic Press.

Dennell, Robin (1985), 'The hunter-gatherer/agricultural frontier in prehistoric temperate Europe' In The Archaeology of Frontiers and Boundaries, ed. by S. Green/S. Perlman, Orlando: Academic Press, 113-140.

Diamond, Jared (1997), Guns, Germs and Steel: The Fates of Human Societies, New York: W. W. Norton.

Fischer, Anders (2002), 'Food for feasting? An evaluation of explanations of the neolithisation of Denmark and southern Sweden' in The Neolithisation of Denmark - 150 Years of Debate (Sheffield Archaeological Monographs, 12), ed. by A. Fischer/K. Kristensen, Sheffield: J.R. Collis Publications, 343-393.

Fort, Joaquim (2012), 'Synthesis between demic and cultural diffusion in the Neolithic transition in Europe' in PNAS 109, no. 46, 18669-18673.

Golitko, Mark/Keeley, Lawrence (2007), 'Beating ploughshares back into swords: Warfare in the Linearbandkeramik' in Antiquity 81, 332-342.

Gkiasta, Marina et al. (2003), 'Neolithic transition in Europe: The radiocarbon record revisited' in Antiquity 77, 45-62.

Haak, Wolfgang et al. (2010), 'Ancient DNA from European early neolithic farmers reveals their near eastern affinities' in PLoS Biology 8, no. 11, 1-16.

Hobbes, Thomas [1651] (2010), Leviathan, or the matter, forme, and power of a commonwealth, ecclesiasticall and civill, ed. by I. Shapiro, Yale: Yale University Press.

Keeley, Lawrence. H./Golitko, Mark (2004), 'First farmers of Central Europe' in Ancient Europe; 8000 B.C. - 1000 A.D. Encyclopaedia of the Barbarian World, ed. by P. Bogucki/P. J. Crabtree, New York: Charles Scribners \& Sons, 259-266.

Klassen, Lutz (2012), 'Axes of Alpine jade from southern Scandinavia and northernmost Germany' in Danish Journal of Archaeology 1, no. 1, 86-89.

North, Douglass C./Thomas, Robert P. (1977), 'The first economic revolution' in The Economic History Review 30, 229-241.

Prebisch, Raùl (1950), The Economic Development of Latin America and Its Principal Problems, UN document no. E/CN.12/89/Rev.1, Lake Success, New York: United Nations.

Price, T. Douglas/ Brown, J. (1985), Prehistoric Hunter-gatherers: The Emergence of Cultural Complexity, San Diego, CA: Academic Press. 
Price, T. Douglas (2000), 'The introduction of farming in northern Europe' in Europe's First Farmers, ed. by T. D. Price, Cambridge: Cambridge University Press, 260-300.

Raemaekers, Daan (1999), The Articulation of a 'New Neolithic'. The Meaning of the Swifterbant Culture for the Process of Neolithisation in the Western Part of the North European Plain (4900-3400), Leiden: Leiden University, https://openaccess.leidenuniv.nl/ handle/1887/13516

Ricardo, David (1817), On the Principles of Political Economy and Taxation, London: John Murray, http://www.econlib.org/library/Ricardo/ricP.html

Scheu, Amelie et al. (2007), 'Ancient DNA provides no evidence for independent domestication of cattle in Mesolithic Rosenhof, Northern Germany' in Journal of Archaeological Science XX, 1-8.

Service, Elman R. (1966), The Hunters, Prentice-Hall, NJ: Englewood Cliffs.

Singer, Hans W. (1950), 'The distribution of gains between investing and borrowing countries', in American Economic Review 40, 473-485.

Skoglund, Pontus et al. (2014), 'Genomic diversity and admixture differs for stone-age scandinavian foragers and farmers' in Science 344, no. 6185, 747-750.

Smith, Adam [1776] (2008), An Inquiry into the Nature and Causes of the Wealth of Nations: A Selected Edition, ed. by K. Sutherland, Oxford: Oxford Paperbacks.

Smith, Vernon. L. (1975), 'The primitive hunter culture, Pleistocene extinction, and the rise of agriculture' in Journal of Political Economy 83, no. 4, 727-755.

Sørensen, Lasse/Sabine, Karg (2012), 'The expansion of agrarian societies towards the North - New evidence for agriculture during the Mesolithic/Neolithic transition in Southern Scandinavia' in Journal of Archaeological Science XXX, 1-17.

Svizzero, Serge (2014), 'Pre-neolithic economy' in History of Economic Ideas XXII, no. 2, $11-26$.

Terberger, Thomas/Hartz, Sönke/Kabacinski, Jacek (2009), 'Late hunter-gatherer and early farmer contacts in the southern Baltic - A discussion', in Neolithisation-workshop EAAConference Cracow September 2006, ed. by H. Glorstad/Ch. Prescott. Lindome: Bricoleur Press, 257-298.

Verhart, Leonardus. B. (2000), Times Fade Away. The Neolithization of the Southern Netherlands in an Anthropological and Geographical Perspective (Archaeological Studies Leiden University, 6), Leiden.

Williamson, Jeffrey G. (2008), 'Globalization and the great divergence: Terms of trade booms, volatility and the poor periphery, 1782-1913' in European Review of Economic History 12, no. 3, 355-391.

Weisdorf, Jacob L. (2003), 'Stone age economics: The origins of agriculture and the emergence of non-food specialists', Discussion Paper no 03-34, Institute of Economics, University of Copenhagen, Available at http://www.econ.ku.dk/english/research/publications/wp/2003/ 0334.pdf/.

Weisdorf, Jacob L. (2005), 'From foraging to farming: Explaining the neolithic revolution' in Journal of Economic Surveys 19, no. 4, 561-586.

Weisdorf, Jacob L. (2009), 'Why did the first farmers toil? Human metabolism and the origins of agriculture' in European Review of Economic History 13, no. 2, 157-172.

Zvelebil, Marek/Rowley-Conwy, Peter (1984), 'Transition to farming in northern Europe: a hunter-gatherer perspective' in Norwegian Archaeology Review 17, 104-127.

Zvelebil, Marek (2001), 'The agricultural transition and the origins of Neolithic society in Europe' in Documenta Praehistorica XXVIII, 1-26.

Zvelebil, Marek (2008), 'Innovating hunter-gatherers: The Mesolithic in the Baltic', in Mesolithic Europe, ed. by G. Bailey, Cambridge: Cambridge University Press, 18-59. 